\title{
E Identifying risk factors for replacement cranioplasty after decompressive craniectomy
}

\author{
Douglas L. Brockmeyer, MD \\ Department of Neurosurgery, Division of Pediatric Neurosurgery, Primary Children's Hospital, University of Utah, \\ Salt Lake City, Utah
}

I $\mathrm{N}$ this issue of the Journal of Neurosurgery: Pediatrics, Rocque et al. ${ }^{4}$ present a high-quality, multicenter, retrospective study analyzing the effects of various clinical factors on postcranioplasty infection and resorption in children who previously underwent decompressive craniectomy. Thirteen centers contributed 359 patients under 19 years of age, with a mean age of 8.4 years at the time of cranioplasty. The clinical variables analyzed included the indication for craniectomy, history of abusive head trauma, bone storage method (frozen or abdomen), bone fixation method, drain use, bone graft size, presence of other implants (primarily ventriculoperitoneal [VP] shunts), fluid collections, age at craniectomy, and time between craniectomy and cranioplasty. Study endpoints were either infection or bone resorption, with bone resorption defined as the need for a repeat trip to the operating room for reparative cranioplasty.

The authors found that $38(10.5 \%)$ cases were complicated by infection, with the presence of cranial implants (mainly VP shunts), gastrostomy tubes, or ventilator dependence being significantly related to infection on multivariate analysis. Of the 240 patients who underwent replacement cranioplasty with their own bone flaps, $21.7 \%$ had enough resorption to require repeat surgery (in the treating surgeon's opinion), with patient age as the sole predictive clinical variable. In fact, on multivariate analysis, a decreased risk for resorption by $1 \%$ was found with every 1-month increase in patient age. Taken together, approximately $32 \%$ of patients had a complication, a very high number. However, this is in line with previously published literature and should be taken in context, as this patient group is at very high risk for complications to begin with. This subject has been previously addressed in the pediatric neurosurgical literature, but only in retrospective, single-center studies. The inclusion of multiple centers in this analysis reduces the obvious institutional and referral biases, which have been major limitations of previous work.
Given the frequency at which decompressive hemicraniectomy is performed in pediatric neurosurgery, this article addresses a timely and important topic. The 2012 Guidelines for the Acute Medical Management of Severe Traumatic Brain Injury in Infants, Children, and Adolescents $^{3}$ recommend considering decompressive hemicraniectomy in patients with increased intracranial pressure refractory to medical management or those who show early signs of neurologic deterioration or herniation. Although the timing, method, and long-term effect of decompressive craniectomy are yet to be determined, it has been successfully employed in several influential studies ${ }^{2,5}$ and shows no sign of going out of favor. Therefore, it is incumbent on pediatric neurosurgeons to understand the potential sequelae of this procedure.

This study provides information about some of those sequelae. For pediatric neurosurgeons, knowing risk factors that may contribute to cranioplasty complications, namely infection or resorption, is extremely helpful. Some factors may be modifiable, such as the method of bone fixation, the use of drains, or even the timing of VP shunt or gastrostomy tube placement. Other factors, such as patient age or the size of the cranioplasty, may be unmodifiable or only minimally modifiable given the clinical circumstances. However, the knowledge provided by this paper can inform discussions with parents and help surgeons make better intraoperative decisions. Either way, each patient receives more rational, evidence-based care as a result.

In the limitations section of their paper, Rocque et al. acknowledge some of the drawbacks of their study. Unfortunately, one previously published clinical risk factor not included in the analysis was comminuted skull fracture. ${ }^{1}$ The omission of this variable is minor, but its inclusion may have provided important information in certain clinical circumstances.

Finally, this study raises the question, "How can we, as pediatric neurosurgeons, do better at this procedure?" A $30 \%$ overall complication rate for replacement cranioplas- 
ty coming from a large multicenter study clearly shows us that there is a great deal about calvarial healing and mechanisms of infection that we do not fully understand. So for now, when faced with the situation where replacement cranioplasty is required in a young, ventilator-dependent child with a severe head injury and a shunt and gastrostomy tube, our instincts, as well as this well-designed paper, tell us that all reasonable efforts must be taken to ensure success. As the paper points out, these efforts might include the use of a manufactured cranial prosthesis for the cranioplasty - a very reasonable decision given the information provided by the study.

At this point, replacement cranioplasty is done with enough frequency that a multicenter, prospective, randomized trial comparing the use of a manufactured prosthesis and the use of the patient's own bone flap could likely be organized. After all, we frequently read in the medical literature, "Further study is necessary to fully elucidate these findings," but no further study is done. In the case of this particular scenario, the opportunity is clearly now. https://thejns.org/doi/abs/10.3171/2018.4.PEDS18184

\section{References}

1. Bowers CA, Riva-Cambrin J, Hertzler DA II, Walker ML: Risk factors and rates of bone flap resorption in pediatric patients after decompressive craniectomy for traumatic brain injury. J Neurosurg Pediatr 11:526-532, 2013

2. Jagannathan J, Okonkwo DO, Dumont AS, Ahmed H, Bahari A, Prevedello DM, et al: Outcome following decompressive craniectomy in children with severe traumatic brain injury: a 10 -year single-center experience with long-term follow up. J Neurosurg 106 (4 Suppl):268-275, 2007

3. Kochanek PM, Carney N, Adelson PD, Ashwal S, Bell MJ, Bratton S, et al: Guidelines for the acute medical management of severe traumatic brain injury in infants, children, and adolescents-second edition. Pediatr Crit Care Med 13 (Suppl 1):S1-S82, 2012

4. Rocque BG, Agee BS, Thompson EM, Piedra M, Baird LC, Selden NR, et al: Complications following pediatric cranioplasty after decompressive craniectomy: a multicenter retrospective study. J Neurosurg Pediatr [epub ahead of print June 8, 2018. DOI: 10.3171/2018.3.PEDS17234]

5. Rutigliano D, Egnor MR, Priebe CJ, McCormack JE, Strong $\mathrm{N}$, Scriven RJ, et al: Decompressive craniectomy in pediatric patients with traumatic brain injury with intractable elevated intracranial pressure. J Pediatr Surg 41:83-87, 2006

\section{Disclosures}

The author reports no conflict of interest.

\section{Response}

\section{Brandon G. Rocque, MD, MS, ${ }^{1}$ and Sandi K. Lam, MD²}

1Department of Neurosurgery, University of Alabama at Birmingham, Birmingham, Alabama; and 'Department of Neurosurgery, Baylor College of Medicine, Houston, Texas

We greatly appreciate Dr. Brockmeyer's thoughtful review of our work. As he points out, decompressive craniectomy is a component of guideline-based care for traumatic brain injury and an option for treatment of re- fractory elevated intracranial pressure from other causes. There will continue to be cranial defects in children that must be repaired.

Prior to undertaking the present study, we performed a systematic review of the literature on complications of pediatric cranioplasty. ${ }^{2}$ Eleven studies met the inclusion criteria, providing data on a total of 441 cranioplasties. Analysis of pooled data from these studies showed that patient age and size of bone defect had no effect. For many variables, however, pooling of data for meta-analysis was not possible. In short, it was difficult to draw any meaningful conclusion about risk factors for infection or bone resorption from the existing literature. The variables examined in the present retrospective cohort study were selected based on this literature and were intended to be an exhaustive list. Unfortunately, as Dr. Brockmeyer notes, we did not include comminuted skull fracture in our analysis. This omission was not intentional. Rather, the paper that made note of fracture comminution as a risk factor was published after data collection for our study was already underway. ${ }^{1}$

We agree that an overall complication rate of $30 \%$ for pediatric cranioplasty is alarmingly high. With regard to cranioplasty infection, we found that VP shunt treatment, gastrostomy, and ventilator dependence were independent risk factors. It is possible that the risk of infection could be lowered by performing VP shunt placement or gastrostomy after cranioplasty rather than before. However, the available data give us no insight into whether that strategy would reduce risk. It may be that these risk factors for infection represent markers of underlying conditions that are not modifiable.

With bone resorption, on the other hand, younger age at the time of cranioplasty is the one independent risk factor, and it is clearly not modifiable. A manufactured cranial prosthesis has no risk of resorption, and as we have shown, it is not at higher risk for infection. Therefore, use of a cranial prosthesis has the potential to lower the overall risk of cranioplasty complication substantially. These prostheses are expensive, they do not grow as the patient grows, and there is concern that they may become dislodged. Nevertheless, the reduced risk of resorption may justify their use.

We did not end our manuscript with the ubiquitous call for "further study." This was intentional, in that we believe that this retrospective cohort study with 359 patients was likely as good an analysis of complication risk factors as was realistically feasible. However, we agree with Dr. Brockmeyer that a strategy to lower the complication rate is needed, and a randomized control trial of autograft bone versus cranial prosthesis could likely be organized. The time is now, and we shall henceforth start organizing.

\section{References}

1. Bowers CA, Riva-Cambrin J, Hertzler DA II, Walker ML: Risk factors and rates of bone flap resorption in pediatric patients after decompressive craniectomy for traumatic brain injury. J Neurosurg Pediatr 11:526-532, 2013

2. Rocque BG, Amancherla K, Lew SM, Lam S: Outcomes of cranioplasty following decompressive craniectomy in the pediatric population. J Neurosurg Pediatr 12:120-125, 2013 